\title{
EL DERECHO A LA INFORMACIÓN PÚBLICA EN LA JURISPRUDENCIA CONSTITUCIONAL: ¿UN DERECHO FUNDAMENTAL INCÓMODO?
}

Fernando SILVA GARCÍA*

\section{INTRODUCCIÓN}

Podríamos celebrar la idea del sociólogo Georg Simmel, en el sentido de que el secreto implica una enorme amplificación de la vida, porque en plena publicidad muchas manifestaciones de la existencia no podrían producirse: el secreto permite que surja otro mundo, junto al mundo visible. ${ }^{1}$ Pensaríamos que dichas aseveraciones son verdaderas con respecto a la vida privada del individuo y las relaciones sociales. Pero qué sucede con la vida pública; qué ocurre con esas ideas en el ámbito de la democracia; allí en donde la legitimidad y las facultades de los representantes (poderes públicos) está condicionada por el respeto a los intereses de los individuos y de la sociedad. ¿Los representantes pueden tener secretos frente a sus representados? Y es aquí en donde el pensador alemán realiza una excepción a su tesis, al reconocer que la democracia persigue la publicidad como un estado deseable en sí mismo, en virtud de que todos deben conocer los hechos y circunstancias que les conciernen, pues sólo así podrán decidir al respecto: el saber implicaría ya una incitación psicológica a participar. Y es a partir de esa diferenciación entre vida privada y pública en que comienza una interesante interacción evolutiva: lo que por su esencia es público y por su contenido interesa a todos, acaba haciéndose cada vez más público externamente, en su forma sociológica; y lo que se refiere sólo al

* Doctor en derecho público.

1 Simmel, Georg, El secreto y las sociedades secretas, Madrid, Sequitur, 2010, p. 57. 
yo, a los asuntos centrípetos del individuo, adquiere una forma sociológica cada vez más privada, más apta para permanecer en secreto. ${ }^{2}$

Como se sabe, las últimas reformas constitucionales y legales sobre el derecho fundamental a la información pública han tenido una clara vertiente garantista, y un impacto manifiesto en el sistema jurídico mexicano: se han expedido leyes sobre acceso a la información en cada una de las entidades federativas; se han creado órganos $u$ organismos en todos los estados para garantizar ese derecho fundamental; se les ha dotado de presupuesto y de una estructura medianamente adecuada para garantizar el derecho a la información, al grado de que aquéllos han comenzado a soportar una gran demanda proveniente de la ciudadanía, produciendo altas cargas de trabajo y riesgos de saturación.

Esa respuesta institucional durante las primeras etapas de desarrollo del derecho a la información ha sido muy positiva. El derecho fundamental a la información pública es uno de esos derechos que, con tan sólo verlos en el papel, cumplen una importante sensación de legitimidad y de realismo democrático. Sin embargo, el reconocimiento formal de tal derecho fundamental, la creación de la estructura orgánica y presupuestal para su garantía, son insuficientes para su tutela efectiva dentro del Estado constitucional. Actualmente, el funcionamiento de los órganos u organismos de acceso a la información, la aplicación e interpretación del artículo 6o. constitucional por los tribunales de justicia, así como su regulación legislativa; han comenzado a poner de manifiesto que se trata de un derecho fundamental incómodo incluso para quienes deben garantizarlo, pues al final del día, los individuos que encarnan los poderes públicos dentro del Ejecutivo, Legislativo y Judicial, se han percibido como víctimas de la proyección garantista de dicho derecho fundamental.

Esa problemática cultural no es propia de nuestro país, sino que se presenta a escala mundial. La prensa ha apuntado que Julian Assange, fundador de WikiLeaks es perseguido por la policía de 188 países, por haber divulgado información democráticamente relevante que EUA quería mantener oculta, tras la filtración de documentos sobre la guerra de Afganistán e Irak, entre otras comunicaciones diplomáticas. ${ }^{3} \mathrm{Al}$ respecto, resulta oportuno recordar la consideración de la $\mathrm{SCJN}$ en el sentido que:

Ibidem, pp. 66 y 67.

3 Gellman, Barton, Julian Assange, "Whistle-Blower or Spy? His Belief in the Virtues of Radical Transparency has Turned the Diplomatic World Upside Down", Time, 
(D)entro de un estado constitucional los representantes están al servicio de la sociedad y no está al servicio de los gobernantes, de donde se sigue la regla general consistente en que los poderes públicos no están autorizados para mantener secretos y reservas frente a los ciudadanos en el ejercicio de las funciones estatales que están llamados a cumplir, salvo las excepciones previstas en la ley, que operan cuando la revelación de datos pueda afectar la intimidad, la privacidad y la seguridad de las personas. ${ }^{4}$

En palabras coloquiales, lo que en un principio se tomó como bandera: "protección efectiva del derecho a la información pública"; hoy, una vez que se han comenzado a sentir los primeros resultados de tal derecho en una diversidad de sujetos obligados, se ha tratado de matizar, disolver y, en todo caso, minimizar, bajo el esquema: “...Transparencia sí... sobre los bueyes de mi compadre...". Y es que a todos nos gusta promover la información pública; de los demás. Quienes deben garantizar el derecho a la información pública (legislador, órganos administrativos, organismos autónomos, jueces, etcétera) son al mismo tiempo sujetos centralmente obligados por ese derecho fundamental; es decir, quienes deben desarrollar su contenido deben transparentar cómo deciden, cuánto ganan, cuánto gastan, cuál es su agenda de trabajo, entre muchos otros datos de relevancia democrática.

Junto con esas dificultades culturales, existen particularidades técnico-jurídicas en la interpretación y ponderación del derecho a la información pública, especialmente en los casos en que se halla en conflicto con otros bienes constitucionalmente protegidos. Así, por ejemplo, de entrada, la definición de los contornos y alcances del derecho a la información pública exige una decisión político constitucional sobre dicho concepto: ¿Es información pública la que está en posesión de los poderes del Estado por causa del ejercicio de funciones de derecho público; o bien, es toda aquélla que sea relevante para la democracia, con independencia de que provenga de poderes públicos o de personas de derecho privado? Asimismo, la necesidad de que los particulares obtengan la información pública solicitada en forma oportuna, está en tensión directa con el riesgo de que los datos solicitados contengan información privada de otros particulares, con la consecuente irreparabilidad que, momento a momen-

December 27, 2010/ January 3, 2011, pp. 68-71.

4 Segunda Sala de la SCJN. Contradicción de tesis 333/2009, 11 de agosto de 2010. 
to, produciría una violación de esas características. Y podríamos seguir con las dificultades prácticas y hermenéuticas.

En definitiva, el derecho a la información pública es un derecho amigo de la sociedad, de la prensa, de la educación, de la libertad; al tiempo que es un derecho enemigo del control, de la concentración, de la arbitrariedad, de los regímenes autoritarios. Es un derecho que en México ha sido impulsado por la clase política (Poder Reforma; Congreso de la Unión, legislaturas locales), y que, paradójicamente, resulta incómodo para la política; en definitiva, es un derecho cuya ineficacia pone en riesgo la democracia constitucional. Como veremos, precisamente, esas oscilaciones están presentes en la jurisprudencia de la SCJN.

\section{FUNDAMENTO}

De diversos pronunciamientos de la SCJN podríamos afirmar que el fundamento del derecho a la información pública es la democracia. El alto tribunal ha reconocido que, en una primera etapa, el derecho a la información estaba limitado a constituir, solamente, una garantía electoral subsumida dentro de la reforma política de esa época, que obligaba al Estado a permitir que los partidos políticos expusieran ordinariamente sus programas, idearios, plataformas y demás características inherentes a tales agrupaciones, por medio de los medios masivos de comunicación; posteriormente; en una segunda etapa, el tribunal pleno amplió sus alcances para establecer que el derecho a la información, estrechamente vinculado con el derecho a la verdad, exige que las autoridades se abstengan de dar a la comunidad información manipulada, incompleta o falsa, so pena de incurrir en violación grave a las garantías individuales en términos del artículo 97 constitucional; en una tercera etapa, la SCJN amplió la comprensión de ese derecho para entenderlo como garantía individual, limitada por los intereses nacionales y los de la sociedad, así como por el respeto a los derechos de terceros; ${ }^{5}$ asimismo, en una cuarta etapa, el derecho a la información se ha llegado a entender como una

5 Derecho a la información. La Suprema Corte interpretó originalmente el artículo 6o. constitucional como garantía de partidos políticos, ampliando posteriormente ese concepto a garantía individual y a obligación del estado a informar verazmente (Registro: 191,981. Tesis aislada. Materia(s): Constitucional, Novena Época, Pleno, Semanario Judicial de la Federación y su Gaceta, t. XI, abril de 2000. tesis: P. XLV/2000, p. 72). 
garantía social. ${ }^{6}$ En ese sentido, la SCJN ha destacado que la vertiente individual del derecho a la información ${ }^{7}$ tiene por objeto maximizar el campo de la autonomía personal, posibilitando el ejercicio de la libertad de expresión y pensamiento en un contexto de mayor diversidad de datos, voces y opiniones; mientras que, por otro lado, el derecho de acceso a la información como derecho colectivo o garantía social cobra un marcado carácter público en tanto que funcionalmente tiende a revelar el empleo instrumental de la información no sólo como factor de autorrealización personal, sino como mecanismo de control institucional, pues se trata de un derecho fundado en una de las características principales del gobierno democrático y republicano, que es el de la publicidad de los actos de gobierno y la transparencia de la administración. ${ }^{8}$

Desde hace varias décadas, se ha dejado clara la relación indisoluble entre el derecho a la información, la libertad de expresión y el sistema democrático al interpretarse que: si el Estado tiene la obligación de proteger el derecho a la información, implícito ya en todo sistema democrático en que el voto de los ciudadanos debe ser un voto informado y no un voto a ciegas, ese derecho implica la obligación de no entorpecer el uso de los medios de difusión masiva de ideas, y prohíbe que el Estado se erija en guardián tutelar de la cantidad o calidad de medios de difusión que en su propio criterio estima que deben existir en el país, como si paternalmente

6 Información. Derecho a la, establecido por el artículo 6o. de la Constitución Federal (Registro: 206,435. Tesis aislada. Materia(s): Constitucional. Octava Época, Segunda Sala, Semanario Judicial de la Federación, t. X, agosto de 1992. tesis: 2a. I/92, p. 44).

7 La SCJN ha interpretado que el derecho a la información implica la obligación del Estado de difundir y garantizar que las entidades de cualquier índole brinden a todo individuo la posibilidad de conocer aquella información que, incorporada a un mensaje, tenga un carácter público y sea de interés general, es decir, todos los datos, hechos, noticias, opiniones e ideas que puedan ser difundidos, recibidos, investigados, acopiados, almacenados, procesados o sistematizados por cualquier medio, instrumento o sistema. Comisión Nacional para la Protección y Defensa de los Usuarios de Servicios Financieros (Condusef). La atribución que le otorga el artículo 11, Fracción XV, de la Ley relativa, para verificar que la información sobre productos y servicios financieros difundida por las instituciones financieras no induzca al error o a la inexactitud, tiende a velar por el derecho que en términos del artículo 6o. de la Constitución federal asiste a los usuarios (Registro: 187,600. Tesis aislada. Materia(s): Constitucional, Administrativa, Novena Época, Segunda Sala, Semanario Judicial de la Federación y su Gaceta, t. XV, marzo de 2002, tesis: 2a. XIX/2002, p. 422).

8 ACCESO A LA INFORMACIÓN. SU NATURALEZA COMO GARANTÍAS INDIVIDUAL Y SOCIAL, Novena Época, Pleno, jurisprudencia 54/2008. 
pudiese controlar la cantidad y calidad de la difusión de las ideas. ${ }^{9}$ En ese orden de ideas, el Pleno de la SCJN ha encontrado que las concesiones relativas al espectro radioeléctrico están condicionadas por los derechos fundamentales, máxime que la radiodifusión constituye una actividad de interés público que cumple una función social de relevancia trascendental para la nación. ${ }^{10}$

\section{OBJETO: CONTORNOS DEL DERECHO A LA "INFORMACIÓN PÚBLICA"}

El objeto de un derecho fundamental o su contenido constitucionalmente protegido está integrado por un haz de facultades o por un conjunto de posibilidades de actuación que tienen los individuos frente al Estado, así como por el sistema de garantías que la Constitución reconoce a sus titulares a esos efectos. De forma tal que el objeto emerge al momento de definir los alcances de la materia concretamente protegida por cada derecho fundamental, estableciendo una línea que vendría a dividir dicho ámbito tutelado de aquella otra parte que estaría fuera de la circunscripción constitucionalmente salvaguardada. Así, por ejemplo, se ha establecido que el objeto de la libertad de expresión no comprende ni incluye el denominado hate-speech (la justificación del nazismo), por implicar una especie de abuso del mencionado derecho fundamental. ${ }^{11}$

La Segunda Sala de la SCJN, en la Contradicción de tesis 333/2009, resuelta el 11 de agosto de 2010 respondió a una importante interro-

9 RADIODIFUSORAS. LIBERTAD DE EXPRESIÓN (Registro: 912,097. Tesis aislada. Materia(s): Administrativa, Séptima Época, tribunales colegiados de circuito, Apéndice 2000 , t. III, administrativa, P.R. TCC, tesis: 532, p. 493. Genealogía: Informe 1981, Tercera Parte, tribunales colegiados de circuito, tesis 28, p. 52, Semanario Judicial de la Federación, Séptima Época).

10 ESPECTRO RADIOELÉCTRICO. A LAS CONCESIONES RELATIVAS SON APLICABLES LOS PRINCIPIOS CONTENIDOS EN EL ARTÍCULO 134 DE LA CONSTITUCIÓN POLÍTICA DE LOS Estados Unidos MEXICANOS, CONJUNTAMENTE CON LOS ESTABLECIDOS EN LOS NUMERALES QUE CONFORMAN EL CAPÍTULO ECONÓMICO DE ÉSTA, Y PREFERENTEMENTE LOS RELATIVOS A LOS DERECHOS FUNDAMENTALES DE LOS GOBERNADOS, Novena Época, Pleno, jurisprudencia 72/2007.

11 STEDH Lehideux e Isorni, 23 de septiembre de 1998. Véase Aba Catoira, Ana. La limitación de los derechos en la jurisprudencia del Tribunal Constitucional Español. Valencia: Tirant lo blanch, 1999, pp. 127-133. Véase Silva Meza, Juan N., Silva García, Fernando. Derechos fundamentales: bases para la reconstrucción de la jurisprudencia constitucional, México, Porrúa, 2009. 
gante: ¿es información pública exclusivamente aquel conjunto de datos cuyo origen proviene de los poderes constituidos; o bien, dicho concepto comprende también los datos cuyo origen proviene de particulares pero que está en posesión de los poderes públicos? Para la Sala, de la lectura del artículo 6o., fracción I, constitucional, en relación con los numerales 1 y 2 de la Ley Federal de Transparencia y Acceso a la Información Pública Gubernamental, el concepto de información pública comprende todos los datos que se encuentren en posesión de cualquier autoridad, entidad, órgano y organismo federal, estatal y municipal, por lo cual dicha información es susceptible, en principio, de divulgarse a terceros en los términos previstos por el legislador en dicho ordenamiento legal. Sin embargo, la Sala consideró que, para que sea posible catalogar como "información pública" al conjunto de datos provenientes de particulares, no basta que aquélla se encuentre en posesión de los poderes públicos, sino que es necesario que tal información de particulares haya sido recabada por las autoridades del Estado en ejercicio de funciones de derecho público. Dentro de un Estado constitucional los representantes están al servicio de la sociedad y no está al servicio de los gobernantes, de donde se sigue la regla general consistente en que los poderes públicos no están autorizados para mantener secretos y reservas frente a los ciudadanos en el ejercicio de las funciones estatales que están llamados a cumplir, salvo las excepciones previstas en la ley, que operan cuando la revelación de datos pueda afectar la intimidad, la privacidad y la seguridad de las personas. En ese tenor, información pública es el conjunto de datos de autoridades o particulares en posesión de cualquier autoridad, entidad, órgano y organismo federal, estatal y municipal, obtenidos por causa del ejercicio de funciones de derecho público ${ }^{12}$, considerando que en este ámbito de actuación rige la obligación de éstos de rendir cuentas y transparentar

12 En tal sentido, la Segunda Sala de la Suprema Corte de Justicia de la Nación dejó apuntado desde el Amparo en Revisión 1922/2009, resuelto el treinta de junio de dos mil diez, por unanimidad de votos, que: “(...) de la lectura del artículo 6o., fracción I, constitucional, en relación con los numerales 1 y 2 de la Ley Federal de Transparencia y Acceso a la Información Pública Gubernamental, el concepto de información pública comprende todos los datos que se encuentren en posesión de cualquier autoridad, entidad, órgano y organismo federal, estatal y municipal, por lo cual dicha información es susceptible, en principio, de divulgarse a terceros en los términos previstos por el legislador en dicho ordenamiento legal. Por tanto, en principio, en el sistema jurídico mexicano constituye información pública, susceptible de darse a conocer a los particulares que lo soliciten, tanto el conjunto de datos concerniente a los poderes constituidos, como también aquella 
sus acciones frente a la sociedad, en términos del artículo 6o., fracción I, de la Constitución Política de los Estados Unidos Mexicanos, en relación con los numerales 1, 2, 4 y 6 de la Ley Federal de Transparencia y Acceso a la Información Pública Gubernamental. ${ }^{13}$

\section{DEBERES NEGATIVOS Y POSITIVOS}

En las Acciones de Inconstitucionalidad acumuladas 76/2008, 77/2008 y 78/2008, resueltas el 25 de septiembre de 2008, el Pleno de la SCJN recordó que los derechos fundamentales implican tanto deberes de abstención (obligaciones de no hacer), como también deberes positivos de promoción (obligaciones de hacer) a cargo de los poderes constituidos, a fin de que sea materialmente posible su efectiva salvaguarda. En ese sentido, el Pleno interpretó que el artículo 6o. de la Constitución federal establece que los poderes públicos federales y locales (principalmente el legislador) deben crear a los órganos especializados e imparciales, con autonomía operativa, de gestión y de decisión, que resulten idóneos y necesarios para la tutela efectiva del derecho a la información. Dicha premisa sirvió para estimar que es inconstitucional la fusión y/o incorporación del órgano encargado de la protección del derecho a la información pública, dentro de la Comisión Estatal de Derechos Humanos. Para el Pleno, la Constitución ha establecido un mandato de ordenación específico y vinculante para todos los órdenes jurídicos federales y locales, en el sentido de establecer de manera separada y autónoma, por un lado, un instituto de control y vigilancia de acceso a la información y, por otro lado, una comisión estatal de derechos humanos (artículos 6o. y 102, apartado B, constitucionales). Por tanto, el Pleno estimó que la Constitución local impugnada había ido más allá del margen de configuración que la norma suprema otorga a los órdenes jurídicos locales, toda vez que ha fusionado a las dos instituciones antes referidas en la llamada "Comisión

información cuyo origen proviene de particulares, pero que está en posesión de las autoridades por razón del ejercicio de funciones de derecho público (...)”.

13 Registro 164032, Novena Época, Segunda Sala, Semanario Judicial de la Federación y su Gaceta, XXXII, agosto de 2010, p. 463, tesis: 2a. LXXXVIII/2010. Tesis aislada, materia(s): constitucional, administrativa. INFORMACIÓN PÚBLICA. ES AQUELLA QUE SE ENCUENTRA EN POSESIÓN DE CUALQUIER AUTORIDAD, ENTIDAD, ÓRGANO Y ORGANISMO FEDERAL, ESTATAL Y MUNICIPAL, SIEMPRE QUE SE HAYA OBTENIDO POR CAUSA DEL EJERCICIO DE FUNCIONES DE DERECHO PÚBLICO. 
Estatal de Derechos Humanos y Acceso a la Información Pública”, lo que representa una distorsión injustificada de la distribución orgánica constitucionalmente prevista, en contravención a los principios de autonomía, especialización y protección efectiva de los derechos humanos previstos en los artículos 6o. y 102, apartado B, de la norma suprema.

\section{LÍMITES}

Para la SCJN, el derecho a la información pública se halla sujeto a limitaciones sustentadas en la protección de la seguridad nacional y en el respeto tanto de los intereses de la sociedad, como de los derechos de terceros (intimidad, vida privada, etcétera); restricciones que, inclusive, han dado origen a la figura jurídica del secreto de información que se conoce como reserva de información o secreto burocrático. ${ }^{14}$ Por ejemplo, la SCJN ha resuelto que el derecho a la información no es violado por la legislación que restringe la expedición de copias certificadas de documentos y constancias de archivo, así como de acuerdos asentados en los libros de actas de los ayuntamientos sólo a las personas que tengan interés legítimo y siempre que no se perjudique el interés público, pues aquéllos involucran la discusión y resolución de intereses de diversa índole (municipal, estatal, nacional, social y privados). ${ }^{15}$

En una línea de pensamiento semejante, la Corte resolvió que son válidas las disposiciones legales que establecen que la Comisión Nacional de los Derechos Humanos tiene facultades para decidir discrecionalmente si entrega o no pruebas y documentos tanto a las autoridades, como a los

14 Derecho a la información. Su EJERCiCio SE ENCUENTRA LiMitado tanto POR LOS INTERESES NACIONALES Y DE LA SOCIEDAD, COMO POR LOS DERECHOS DE TERCEROS, Registro 191,967, Tesis aislada, materia(s): constitucional, Novena Época, Pleno, Semanario Judicial de la Federación y su Gaceta, t. XI, abril de 2000. tesis: P. LX/2000, p. 74).

15 Derecho a la información. El ARTículo 112, FRACCiÓN VII, DE LA Ley ORGÁNICA Municipal PARA El ESTADO DE GuANAJUATO, NO LO VIOLA POR LIMITAR LA EXPEDICIÓN DE COPIAS CERTIFICADAS DE DOCUMENTOS Y CONSTANCIAS DE ARCHIVO, ASÍ COMO DE ACUERDOS ASENTADOS EN LOS LIBROS DE ACTAS DE LOS AYUNTAMIENTOS, SÓLO A LAS PERSONAS QUE TENGAN INTERÉS LEGÍTIMO Y SIEMPRE QUE NO SE PERJUDIQUE EL INTERÉS PÚBLICO, Registro 191,966, tesis aislada, materia(s): constitucional, administrativa, Novena Época, Pleno, Semanario Judicial de la Federación y su Gaceta, t. XI, abril de 2000. tesis: P. LXI/2000, p. 71. 
particulares solicitantes, máxime que tal regulación no está prohibiendo la entrega de documentos. ${ }^{16}$ Asimismo, el Tribunal Constitucional del país ha interpretado que

es válida la Ley del Seguro Social que dispone que los documentos, datos e informes que los trabajadores, patrones y demás personas proporcionen al Instituto Mexicano del Seguro Social, son estrictamente confidenciales y no pueden comunicarse o darse a conocer en forma nominativa e individual, salvo cuando se trate de juicios y procedimientos en los que dicho instituto sea parte y en los casos previstos por la ley. ${ }^{17}$ El Pleno también ha establecido que los expedientes judiciales que no hayan causado estado, las opiniones, recomendaciones o puntos de vista que formen parte del proceso deliberativo de los servidores públicos, mientras no sea adoptada la decisión definitiva, constituyen información reservada.

Sin embargo, se ha estimado que "en aquellos supuestos en los cuales la difusión de dicha información producirá mayores beneficios para la sociedad que los daños que pudieran provocarse con su divulgación, debe hacerse una excepción a la regla general, privilegiando la transparencia y difusión de la información respectiva". ${ }^{18}$ Otro ejemplo de tales limitantes, lo constituye la declaratoria de constitucionalidad de la Ley de Vías Generales de Comunicación,

al prohibir válidamente la divulgación de la información obtenida por la Secretaría de Comunicaciones y Transportes a través de sus inspectores, de las empresas concesionarias o permisionarias que construyan, establez-

16 DERECHO A LA INFORMACIÓN Y GARANTÍA DE AUDIENCIA. LOS ARTÍCULOS 48 DE LA LEY DE LA COMISIÓN NACIONAL DE DERECHOS HuMANOS Y 104 DE SU REGLAMENTO INTERNO, NO LOS VIOLAN PORQUE AUN CUANDO ESTABLECEN COMO FACULTAD DISCRECIONAL LA EXPEDICIÓN DE DOCUMENTOS Y COPIAS, NO LA PROHÍBEN, Registro 191,980, tesis aislada, materia(s): constitucional, administrativa, Novena Época, Pleno, Semanario Judicial de la Federación y su Gaceta, t. XI, abril de 2000. tesis: P. XLVI/2000, p. 74.

17 Derecho a la información. El artículo 22 DE LA LEY DEL Seguro Social NO LO VIOLA AL ESTABLECER LA CONFIDENCIALIDAD DE LOS DOCUMENTOS, DATOS E INFORMES PROPORCIONADOS AL INSTITUTO RELATIVO, YA QUE PERMITE PROPORCIONARLOS PARA JUICIOS Y PROCEDIMIENTOS LEGALES, Registro 191,979, tesis aislada, materia(s): constitucional, administrativa, laboral, Novena Época,Pleno, Semanario Judicial de la Federación y su Gaceta, t. XI, abril de 2000. tesis: P. XLVII/2000, p. 72.

18 INFORMACIÓN RESERVADA. EXCEPCIÓN A LA PROHIBICIÓN DE SU DIVULGACIÓN, Novena Época, Pleno, jurisprudencia 45/2007. 
can o exploten vías generales de comunicación, o presten servicios conexos a éstas, al estimarse información confidencial que atiende a razones de seguridad nacional y de interés público, para evitar el uso indebido que pueda dársele, en relación con áreas prioritarias (transporte) para el Estado mexicano. ${ }^{19}$

\section{PONDERACIÓN}

\section{Derecho a la información pública vs. derecho a la vida privada de} los sindicatos: caso cuotas sindicales de Pemex

La Segunda Sala de la SCJN resolvió que el monto total al que ascienden las cuotas sindicales aportadas anualmente por los trabajadores de Petróleos Mexicanos no constituye información pública que, sin la autorización del sindicato, deba darse a conocer a los terceros que lo soliciten, ya que constituye un haber patrimonial perteneciente a una persona jurídica de derecho social (sindicato) y un dato que, si bien está en posesión de una entidad gubernamental (Petróleos Mexicanos), se obtiene por causa del ejercicio de funciones ajenas al derecho público, ya que tal información está en poder de dicho organismo descentralizado por virtud del carácter de patrón que tiene frente a sus empleados, por medio de la obligación de retener mensualmente las cuotas sindicales aportadas para enterarlas al sindicato, impuesta por el artículo 132, fracción XXII, de la Ley Federal del Trabajo, siendo que en el ámbito laboral no rige esa obligación a cargo del patrón de rendir cuentas y transparentar acciones frente a la sociedad. Máxime que el monto de las cuotas sindicales forma parte del patrimonio del sindicato y su divulgación importaría, por un lado, una afectación injustificada a la vida privada de dicha persona de derecho social, lo que está protegido por los artículos 6o., fracción II, y 16 constitucionales, por otro lado, una intromisión arbitraria a la libertad sindical, por implicar una invasión a la facultad que tiene el sindicato de decidir si da o no a conocer parte de su patrimonio a terceros, lo que está

19 VÍAs GENERALES DE COMUNICACIÓN. El ARTíCUlO 121 DE LA LEY RELATIVA, AL CONSIDERAR CONFIDENCIALES LOS DATOS OBTENIDOS POR LOS INSPECTORES DE LA SECRETARÍA DE COMUNICACIONES Y TRANSPORTES, NO VIOLA LA GARANTÍA DE ACCESO A LA INFORMACIÓN, Novena Época, Segunda Sala, tesis aislada XLIV, amparo en revisión 50/2008. Rosario Liévana León. 12 de marzo de 2008. Cinco de votos, ponente Genaro David Góngora Pimentel. Secretario: Rómulo Amadeo Figueroa Salmorán.. 
protegido por los artículos 3o. y 80. del Convenio 87, relativo a la Libertad Sindical y a la Protección al Derecho Sindical. ${ }^{20}$

\section{Derecho a la información medioambiental vs. derecho a la vida privada de las empresas: caso Dupont y caso Peñoles}

Los casos Dupont y, posteriormente Peñoles, tuvieron origen por causa de una resolución dictada por el Instituto Federal de Acceso a la Información Pública Gubernamental (IFAI) que denegó la solicitud realizada por una periodista que deseaba hacer públicos los resultados de una auditoría ambiental realizada a dichas empresas, en esencia, con base en el argumento consistente en que la apertura de dichos datos podría afectar, en forma irreversible, datos confidenciales de dichas personas jurídicas. En dichos asuntos se plantearon importantes interrogantes: ¿Qué sucede cuando los documentos públicos solicitados contienen — no sólo datos personales - sino información medioambiental entremezclada con información empresarial?

Para desentrañar esa dificultad, en algunas discusiones previas a la realización del proyecto de sentencia, salió a relucir el tema relativo a la divisibilidad del átomo. La teoría atómica del siglo XIX creyó que los átomos eran los componentes últimos de la materia y de ahí su nombre por ser indivisibles. Al parecer, el IFAI pensaba que el átomo todavía es indivisible, por denegar la información medioambiental solicitada por el sólo hecho de estar entremezclada con datos de la vida privada de las empresas mencionadas. Teorías posteriores demostraron que el átomo no era indivisible, estaba conformado de protones y neutrones. Actualmente, los estudios de la física de partículas señalan a los quarks, junto con los leptones, como los constituyentes fundamentales de la materia. Diversos tipos de quarks se combinan para formar partículas tales como protones y neutrones. ${ }^{21} \mathrm{La}$

20 Registro 164033, Novena Época, Segunda Sala, Semanario Judicial de la Federación y su Gaceta. XXXII, agosto de 2010, p. 438. tesis: 2a./J. 118/2010. Jurisprudencia. Materia(s): Administrativa. INFORMACIÓN PÚBLICA. EL MONTO ANUAL DE LAS CUOTAS

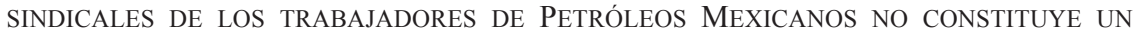
DATO QUE DEBA DARSE A CONOCER A LOS TERCEROS QUE LO SOLICITEN.

${ }^{21}$ Yoichiro Nambu. Quarks: frontiers in elementary particle physics, World Scientific Series, 1985. 
historia científica ya había demostrado, para entonces, que el átomo era divisible. "Si el átomo se puede dividir; luego entonces....". 22

En el amparo en revisión 248/2008 (Caso Dupont) resuelto por la Primera Sala de la SCJN el 1o. de junio de 2009, la destacada proyectista María Amparo Hernández Chong Cuy y el ministro ponente José de Jesús Gudiño Pelayo realizarían una de las aportaciones centrales para definir el alcance del derecho de acceso a la información pública tratándose de datos medioambientales generados voluntariamente por empresas privadas. A ese respecto, la Primera Sala estimó lo siguiente:

Por lo tanto, resulta necesario determinar si la información que es generada voluntariamente por un particular y entregada por él a la autoridad administrativa, puede ser de acceso al público en función de que obra en archivos públicos y en atención exclusivamente a sus contenidos que atañen directamente a cuestiones medioambientales.

¿El derecho a un medio ambiente adecuado pasa por el conocimiento público de determinada información, a pesar de que la misma sea generada por particulares?

(...)

Se estima que toda información de carácter medioambiental en posesión del Estado es por definición información pública, aun cuando el Estado no haya sido quien la generó, a la cual todo particular puede tener acceso.

(...)

Como ya se vio en el caso concreto, además de la información medio ambiental, hay información del agente industrial que optó por auditarse, ya sea de índole administrativa, comercial o de índole industrial. Esta información, por esa precisa razón, no entra dentro de la esfera de la información pública porque, si bien obra en poder de la autoridad, no tiene que ver con su gestión pública, Ni tiene que ver con el medioambiente, sino que es referente al ámbito propio y privado de la empresa auditada.

Así las cosas, agotado el estudio del caso y habiendo resultado fundada la pretensión de las empresas quejosas en el sentido de que la información sobre ella misma es confidencial (aun cuando ello deje a salvo el acceso a la información medioambiental), ha lugar a conceder el amparo y protección de la justicia federal, para el efecto de que el Pleno del Instituto

22 Esta es una de las frases relevantes en la discusión previa a la elaboración de los argumentos para el caso Peñoles, del ahora magistrado Emmanuel Rosales Guerrero con el suscrito. 
Federal de Acceso a la Información Pública Gubernamental, señalado en este juicio como autoridad responsable, deje insubsistente la resolución reclamada y dicte una nueva, en la que dejando intocado lo que no fue materia de este juicio de garantías y considerando los razonamientos establecidos en la presente ejecutoria, resuelva lo que proceda (...).

La Primera Sala de la SCJN concedió el amparo a Dupont en contra de la resolución reclamada, para el efecto de que el Pleno del Instituto Federal de Acceso a la Información Pública Gubernamental dejara insubsistente la resolución reclamada y dictara una nueva, en la que: i) considerara que la información medioambiental solicitada por la periodista es información pública y que, en esa virtud, no le debió haber sido negada, ni por medio de la primigenia calificación como "confidencial" de la misma por parte de la Procuraduría Federal de Protección al Ambiente, ni con base en las razones que se adujeron para su "reserva" (secreto industrial o comercial) por el Pleno del Instituto Federal de Acceso a la Información Pública Gubernamental; ii) clasificara por separado la información privada (empresarial, administrativa e industrial) que consta o pudiera constar en los documentos solicitados por la persona física quejosa, que verse sobre contenidos ajenos al medio ambiente, máxime que esa información, precisamente por ser privada, en principio, no está sujeta a la publicidad y disposición del público, en términos de lo dispuesto en la Ley Federal de Transparencia y Acceso a la Información Pública.

Los importantes avances del caso Dupont fueron complementados por las consideraciones de la Segunda Sala de la SCJN en el caso Peñoles (amparo en revisión 1922/2009), resuelto el 30 de junio de 2010. Así como en Dupont se determinó que la información medioambiental es pública por definición; y que es divisible lo que el IFAI había considerado indivisible; en Peñoles se reconoció que el derecho a la información medioambiental es un derecho fundamental autónomo (lo que vendría a implicar la inconstitucionalidad de toda resolución — como la emitida por el IFAI - que se atreviera a negar en forma absoluta el acceso a los datos de esa naturaleza); y se estableció, no sólo la divisibilidad del contenido de las auditorías medioambientales, sino que se precisó qué es lo público y qué forma parte de la vida privada de las empresas, en dichos supuestos.

En efecto, en el caso Peñoles, la litis consistió en determinar si resultaba o no constitucional la resolución del IFAI que negó en forma absoluta 
la información medioambiental solicitada por una periodista, derivada de una auditoría ambiental practicada a la empresa quejosa, con base en razones de confidencialidad y respeto a la vida privada de dicha persona jurídica. La Segunda Sala consideró que de la interpretación armónica y sistemática de los artículos 4o. y 6o. de la Constitución se advierte la existencia de un derecho fundamental a la información medioambiental, tomando en cuenta que la posibilidad de prevenir efectos negativos sobre el medio ambiente que dañen a los individuos y a la colectividad, precisa de la obtención de información oportuna, idónea y necesaria y que el medio ambiente adecuado, además de estar reconocido como derecho protegido constitucional e internacionalmente, constituye el contexto espacial de subsistencia para el desarrollo y disfrute de los demás derechos esenciales del hombre (vida, salud e integridad personal, entre otros). Para la Sala, ese estado de cosas impone reconocer que el derecho a la información medioambiental conlleva el deber a cargo de los poderes públicos (legislador, juzgadores y autoridades administrativas), en el sentido de establecer las medidas idóneas para que la información sobre cuestiones medioambientales esté siempre disponible para la sociedad (principio interpretativo de máxima publicidad y transparencia), de donde resulta que

son inconstitucionales las resoluciones que denieguen en forma absoluta la obtención de información medioambiental, a pesar de que ello pretenda justificarse en otros intereses legal y constitucionalmente protegidos (derecho a la vida privada de las personas), tomando en cuenta que la protección de una garantía individual no debe llevar al extremo de nulificar el contenido esencial de otra, si se considera que ambas tienen la misma jerarquía normativa y que siempre es posible excluir de la información medioambiental los datos confidenciales de las personas implicadas (divisibilidad del átomo). ${ }^{23}$

Al respecto, la Segunda Sala determinó que en los casos de solicitudes realizadas a la Procuraduría Federal de Protección al Ambiente, a la luz de la Ley Federal de Transparencia y Acceso a la Información

23 Registro 164105, Novena Época, Segunda Sala, Semanario Judicial de la Federación y su Gaceta. XXXII, agosto de 2010, p. 460, tesis: 2a. LXXII/2010, tesis aislada, materia(s): constitucional, DERECHO A LA INFORMACIÓN MEDIOAMBIENTAL. SON INCONSTITUCIONALES LOS ACTOS DE AUTORIDAD QUE DENIEGAN, EN FORMA ABSOLUTA, LA OBTENCIÓN DE AQUÉLLA. 
Pública Gubernamental, sobre la información medioambiental derivada de auditorías ambientales practicadas a empresas en términos del artículo 38 Bis de la Ley General del Equilibrio Ecológico y la Protección al Ambiente, los poderes públicos competentes deben operar de la siguiente forma: 1) abstenerse de denegar, en forma absoluta, la información medioambiental solicitada, so pretexto de proteger otros intereses legales o constitucionales; 2) abstenerse de otorgar, junto con la información medioambiental, datos confidenciales, secretos y privados de las empresas auditadas, pues ello implicaría violación irreversible a sus derechos constitucionales; 3 ) excluir de la información pública medioambiental, la información empresarial de carácter privado; 4) negar información secreta, confidencial y privada de la empresa auditada, y 5) otorgar en versión pública la información derivada de la auditoría ambiental, consistente en: i) los programas preventivos y correctivos derivados de la auditoría ambiental a que se refiere el artículo 38 Bis 1 de la Ley General citada; ii) el diagnóstico básico a que hacen referencia los numerales 17 y 19 del Reglamento de la Ley General del Equilibrio Ecológico y la Protección al Ambiente en Materia de Auditoría Ambiental, y iii) la propuesta de plan de acción a que aluden los artículos 15 y 16 de dicho Reglamento. Mediante ese tratamiento, es posible que las autoridades competentes para resolver lo relativo a las solicitudes de información pública respeten equilibrada, razonable y proporcionalmente tanto los artículos 4o. y 6o. (derecho a la información medioambiental), como los numerales 6o., fracción II, 14 y 16 (derecho a la privacidad de las personas jurídicas), todos de la Constitución. ${ }^{24}$

\section{La facultad del IFAI de armonizar derechos fundamentales en conflicto}

Es claro entender que la Constitución, como norma jurídica, contiene preceptos que se dirigen y vinculan directamente a los gobernados y a los poderes constituidos del Estado. Esas notas son las que la academia

24 Registro 164104, Novena Época, Segunda Sala, Semanario Judicial de la Federación y su Gaceta. XXXII, agosto de 2010, p. 461, tesis: 2a. LXXIII/2010, tesis aislada, materia(s): administrativa, constitucional. DERECHO A LA INFORMACIÓN MEDIOAMBIENTAL. SU RESPETO TRATÁNDOSE DE LAS SOLICITUDES DE DATOS SOBRE AUDITORÍAS AMBIENTALES PRACTICADAS A EMPRESAS PRIVADAS. 
actual destaca para demostrar el valor normativo del ordenamiento supremo: toda autoridad puede y debe aplicar la Constitución directamente, especialmente tratándose de los derechos fundamentales, sin necesidad de que una ley prevea una norma de competencia para ello. ${ }^{25} \mathrm{La}$ aplicación directa de la norma suprema ha sido expresamente autorizada por la SCJN en diversos criterios. ${ }^{26}$

La Constitución, como norma jurídica, vincula a los ciudadanos y a los poderes públicos. En consecuencia, los derechos fundamentales, en cuanto parte integrante de la Constitución, son predicables directamente frente a los poderes públicos (eficacia vertical) y frente a los particulares (eficacia horizontal). A ese respecto, se ha dicho que las dos formas más importantes por medio de las cuales los poderes públicos deben hacer efectivos los derechos fundamentales son: la acción legislativa y la acción jurisdiccional. En primer lugar, el legislador debe de concretar un alcance adecuado de los derechos fundamentales a la hora de regular las relaciones entre particulares; así por ejemplo, cuando reglamenta las relaciones laborales ha de respetar y dar contenido a derechos como la igualdad, la jornada laboral, la huelga, etcétera. Otro tanto sucede con la acción de los jueces y tribunales; cuando éstos resuelven controversias entre los particulares, no sólo deben de evitar que su acción vulnere derechos fundamentales, sino que deben asegurar que estos derechos queden respetados en las relaciones jurídicas entre los propios particulares.

Pero no sólo el legislador y los jueces deben aplicar directamente la Constitución, sino también las autoridades administrativas, sin que ello implique que estas últimas se encuentren autorizadas, en nuestro sistema jurídico, a ejercer un control de constitucionalidad. ${ }^{27}$ Así lo resolvió la

${ }^{25}$ García de Enterría, Eduardo, "Principio de legalidad. Estado material de Derecho y facultades interpretativas y constructivas de la Jurisprudencia en la Constitución", Revista Española de Derecho Constitucional, año 4, núm. 10, 1984. García de Enterría, Eduardo; Fernández, Tomás-Ramón, Curso de derecho administrativo I, 9a. ed., Madrid, Civitas, 1999.

26 “COnstitución Política de los Estados Unidos Mexicanos. Su aplicación DIRECTA CORRESPONDE INDISTINTAMENTE A TODAS LAS AUTORIDADES ORDINARIAS O DE CONTROL CONSTITUCIONAL, SIEMPRE Y CUANDO NO DESAPLIQUEN, PARA ESE EFECTO, UNA LEY SECUNDARIA, Novena Época, Segunda Sala, tesis aislada CLXII/2008.

27 La aplicación directa del texto constitucional tiene como límite el llamado monopolio de los jueces constitucionales del control de constitucionalidad de las leyes que opera en México. Es decir, en caso de que la aplicación directa de la Constitución requerida en un determinado caso concreto, conlleve, además, dejar de lado una ley secundaria, 
Segunda Sala, al considerar que en ocasiones las autoridades administrativas que realizan un control de la legalidad tienen competencia para resolver asuntos en que están involucrados los derechos de la persona, lo que sucede en el caso del IFAI, cuyas resoluciones guardan relación estrecha con las tensiones que, en algunos casos, se producen entre el derecho a la información, contenido en el artículo 6o. de la Constitución y el derecho a la vida privada, tutelado en los numerales 6o., fracción II, 14 y 16 citados de la Ley Suprema. Desde esa óptica, para la Segunda Sala de la SCJN es posible determinar que dicha autoridad viola los deberes de exacta aplicación del derecho, así como de fundamentación y motivación adecuada, previstos en los artículos 14 y 16 citados, de interpretar las leyes sin considerar los efectos que ello pueda producir en todos y cada uno de los derechos legales, internacionales y constitucionales en conflicto; esto es, en caso de que, en ejercicio del control de legalidad que tiene encomendado aplique las leyes de la materia en forma irrazonable, poniendo en riesgo el goce efectivo de alguno de los derechos de la persona, máxime que el artículo 6o. de la Ley Federal de Transparencia y Acceso a la Información Pública Gubernamental dispone que el derecho de acceso a la información pública se interpretará conforme a la Constitución General de la República, a la Declaración Universal de los Derechos Humanos, al Pacto Internacional de Derechos Civiles y Políticos, a la Convención Americana sobre Derechos Humanos, a la Convención Sobre la Eliminación de Todas las Formas de Discriminación Contra la Mujer, y demás instrumentos internacionales suscritos y ratificados por el Estado

ese tipo de actividad debe entenderse encomendada exclusivamente a los jueces constitucionales del Poder Judicial de la Federación, pues sólo ellos tienen competencia para controlar la constitucionalidad de los actos y leyes de los poderes públicos. Así se desprende de la siguiente tesis: "CONTROL DIFUSO DE LA CONSTITUCIONALIDAD DE NORMAS GENERALES. No LO AUTORIZA EL ARTíCUlo 133 DE LA CONSTITUCIÓN, Registro 193,435, jurisprudencia, materia(s): constitucional, Novena Época, Pleno, Semanario Judicial de la Federación y su Gaceta, t. X, agosto de 1999. tesis: P./J. 74/99, p. 5. Por ende, las autoridades ajenas a los jueces constitucionales del Poder Judicial de la Federación deben aplicar directamente la Constitución hasta el límite de lo dispuesto en una ley formal y material. Es decir, todos los poderes públicos tienen el deber de aplicar e interpretar los contenidos constitucionales sin que ello implique que tengan facultades para inaplicar la obra del legislador democrático a partir de un juicio propio y autónomo de inconstitucionalidad de la norma legal respectiva. Véase Silva Meza, Juan N. Derechos Fundamentales. Bases..., cit. 
mexicano, así como a la interpretación (jurisprudencia) que de ellos hayan realizado los órganos internacionales especializados. ${ }^{28}$

VI. EL RIESGO DE SENTENCIAS CONSTITUCIONALES

INCONVENCIONALES EN MATERIA DE DERECHO A LA INFORMACIÓN:

¿LA COMISIÓN NACIONAL DE DERECHOS HuMANOS

ESTÁ IMPOSIBILITADA PARA SOLICITAR INFORMACIÓN PÚBLICA?

Existen algunos pronunciamientos de la Corte Interamericana de Derechos Humanos (CIDH), dirigidos a garantizar en forma eficaz el derecho a la información. Por ejemplo, en el caso La Cantuta vs. Perú, la CIDH determinó que ningún órgano del Estado puede dejar de aportar la información requerida por autoridades judiciales u otras encargadas de la investigación de una situación sobre violación de derechos humanos, ni siquiera bajo argumentos de confidencialidad o secretos de Estado. Para la Corte Interamericana, en caso de violaciones a derechos humanos, las autoridades estatales no se pueden amparar en mecanismos como el secreto de Estado o la confidencialidad de la información, en razones de interés público o seguridad nacional, para dejar de aportar la información requerida por las autoridades judiciales o administrativas encargadas de la investigación o proceso pendientes. ${ }^{29}$

28 Registro 164028, Novena Época, Segunda Sala, Semanario Judicial de la Federación y su Gaceta. XXXII, agosto de 2010, p. 464. tesis: 2a. LXXV/2010, tesis aislada, materia(s): constitucional, administrativa. INSTITUTO FEDERAL DE ACCESO A LA INFORMACIÓN PÚBLICA. DEBE INTERPRETAR LAS LEYES DE SU COMPETENCIA CONFORME A LOS DERECHOS DE LA PERSONA.

29 En dicho asunto, la CIDH también interpretó que la garantía del derecho a la información no puede estar en manos de la autoridad a quien se imputa la comisión del ilícito que se pretende investigar. Cuando se trata de la investigación de un hecho punible, la decisión de calificar como secreta la información y de negar su entrega jamás puede depender exclusivamente de un órgano estatal a cuyos miembros se les atribuye la comisión del hecho ilícito. "No se trata pues de negar que el Gobierno deba seguir siendo depositario de los secretos de Estado, sino de afirmar que en materia tan trascendente, su actuación debe estar sometida a los controles de los otros poderes del Estado o de un órgano que garantice el respeto al principio de división de los poderes..... De esta manera, lo que resulta incompatible con un Estado de Derecho y una tutela judicial efectiva "no es que haya secretos, sino estos secretos escapen de la ley, esto es, que el poder tenga ámbitos en los que no es responsable porque no están regulados jurídicamente y que por tanto están al margen de todo sistema de control...", Caso La Cantuta vs. Perú. 
Al parecer, en forma contraria a la jurisprudencia interamericana, la SCJN resolvió la Acción de Inconstitucionalidad 49/2009 el 9 de marzo de 2010, por mayoría de siete votos contra cuatro, en el sentido de validar el artículo 5o. de la Ley Orgánica de la Procuraduría General de la República (PGR), en que se estableció que sólo podrá "proporcionar información a la Comisión Nacional de Derechos Humanos cuando la solicite en ejercicio de sus funciones, siempre que no ponga en riesgo investigaciones en curso o la seguridad de personas". La CNDH impugnó esta medida mediante un juicio de acción de inconstitucionalidad, porque estimó que la reforma se creó para dotar de facultades discrecionales a la procuraduría a fin de que impida que se investiguen violaciones de derechos humanos cometidas por funcionarios de dicha corporación. El juicio fue promovido por el entonces presidente de la Comisión, José Luis Soberanes, quien en su demanda advirtió que de validarse esta restricción, se anularía la posibilidad de proteger los derechos humanos de abusos cometidos por la PGR. Si la CNDH no tiene acceso a la información en poder de la PGR para recabar pruebas para la substanciación de los procedimientos de queja, no podrá realizar de manera eficiente su labor de protección de los derechos humanos, pues estará imposibilitada para determinar si dichas garantías son respetadas por las autoridades administrativas, lo cual disminuye las posibilidades de defensa de los gobernados. La mayoría de ministros, a propuesta del ministro Fernando Franco González Salas, pasando totalmente inadvertida la jurisprudencia interamericana, llegaron a la conclusión de que la reforma no viola lo dispuesto en la Constitución. En respuesta a la sentencia mayoritaria, del lado de la minoría, los ministros José Ramón Cossío, Juan Silva Meza, Olga Sánchez Cordero y Guillermo Ortiz Mayagoitia coincidieron que con esta medida se vulneran las atribuciones de la CNDH y su labor de defensa de derechos humanos. Advirtieron que esta decisión deja indefensas a las personas que puedan sufrir maltratos, desapariciones o torturas en los que estén involucrados funcionarios de la PGR.

Esta decisión mayoritaria de la SCJN puede ejemplificar una de las regresiones de la jurisprudencia constitucional en materia de acceso a la información pública, y el riesgo de que la jurisprudencia constitucional contravenga el derecho internacional de los derechos humanos. 


\section{V. ¿ASUNTOS PENDIENTES ANTES DE MORIR?}

La revisión de las resoluciones de los órganos u organismos de acceso a la información pública, por parte de los tribunales contencioso administrativos.

A la fecha en que el presente comentario fue entregado para su publicación, se encuentra por resolver la Acción de Inconstitucionalidad 56/2009 promovida por diputados de Campeche, cuya litis central consiste en determinar si el artículo 74 de la de la Ley de Transparencia y Acceso a la Información Pública del Estado de Campeche es o no constitucional por legitimar y permitir que las autoridades (obligadas a dar información) puedan impugnar las resoluciones de la Comisión de Información estatal (órgano constitucional autónomo local) ante el Pleno del Tribunal Superior de Justicia de dicha entidad federativa.

El artículo 6o., fracción IV, constitucional dispone que los mecanismos de acceso a la información deben sustanciarse en forma expedita ante órganos u organismos especializados e imparciales que deben contar con autonomía decisoria, lo cual significa que las resoluciones y la interpretación de la ley que aquéllos emiten en el ejercicio de dicha competencia constitucional no debe admitir injerencias ni estar subordinada a la decisión de los diversos poderes públicos, lo cual implica que sean definitivas e inatacables, en virtud de que, por disposición constitucional, es a aquéllos a quienes compete garantizar el principio de legalidad en ese ámbito, sin perjuicio de que sus resoluciones puedan ser materia de control de regularidad constitucional, a fin de garantizar el respeto de las competencias y garantías institucionales de los sujetos obligados, así como los derechos de terceros, reconocidos en la Constitución local y en la norma suprema, respectivamente.

Por tanto, alguien podría pensar que es inconstitucional sujetar al órgano u organismo previsto para garantizar aquel derecho, a un control de legalidad de las resoluciones que forman parte de su autonomía decisoria. Si bien es verdad que el legislador cuenta con libertad para decidir lo relativo a la configuración orgánica del órgano u organismo de acceso a la información pública (desconcentrado, descentralizado u organismo constitucional autónomo), lo que podría resultar inadmisible es que, con ese propósito, el legislador afecte y disminuya la autonomía decisoria de aquéllos, lo que ocurre cuando se introduce en la ley un diverso recurso ordinario para combatir la legalidad de las resoluciones emitidas por el 
órgano u organismos de acceso a la información, toda vez que: i) dicha situación generaría que la cuidadosa integración, la especialización y la configuración de los órganos u organismos de acceso a la información pública quedara vaciada de contenido, pues ello daría lugar a que el órgano revisor (piénsese en un tribunal administrativo) quedara superpuesto y absorbiera por completo la razón de ser de aquéllos; ii) tal escenario supondría la distorsión del sistema de facultades diseñado en la norma suprema a esos efectos, que ha previsto que los órganos y organismos de acceso a la información, y no los tribunales administrativos, son los competentes para resolver ese tipo de asuntos; iii) también implicaría un claro riesgo para la eficacia del derecho a la información pública, por la dilación que conlleva la duplicación de recursos ordinarios de legalidad (el primero ante el órgano u organismo de acceso a la información y el segundo ante el tribunal administrativo) en detrimento del acceso oportuno a la información solicitada; iv) el órgano revisor (tribunal administrativo) estaría desviando sus facultades por estar resolviendo, en realidad, una controversia institucional (entre el organismo de acceso a la información y el poder público obligado a proporcionarla).

En la referida Acción de Inconstitucionalidad 56/2009, destaca que los artículos 54, fracción XIX bis, de la Constitución de Campeche y 49 de la Ley de Transparencia y Acceso a la Información Pública de dicha entidad, establecen que la Comisión de Transparencia y Acceso a la Información Pública tiene el carácter de órgano constitucional autónomo local, lógicamente con autonomía orgánica y decisoria; lo que implica que, en el ámbito de su competencia, las resoluciones que emite obligan a todos los poderes de la entidad federativa, incluido el Poder Judicial local. Por tanto, parecería que el hecho de que la legalidad de las resoluciones de la Comisión sea revisada y revocable por el Poder Judicial local, que es precisamente uno de los sujetos obligados a dar información a los ciudadanos, podría constituir para algunos comentaristas una violación manifiesta al principio de autonomía decisoria, considerando que el sistema está permitiendo que uno de los sujetos controlados se encuentre facultado para sobreponerse y suplantar al organismo controlador, lo que haría inadecuado el diseño orgánico elegido por el Constituyente local para garantizar que los sujetos obligados (Poderes Ejecutivo, Legislativo y Judicial) resulten conminados a otorgar la información pública solicitada por los ciudadanos, lo que además propiciaría la ineficacia del 
derecho fundamental a la información pública. En ese orden de ideas, lo que para muchos podría resultar inadmisible es sujetar al organismo constitucional autónomo local a un control de legalidad de las resoluciones que forman parte de su autonomía decisoria, sin que ello signifique que la Comisión de Transparencia y Acceso a la Información Pública del Estado de Campeche se ubique como un organismo inmune al control jurídico y al principio de división de poderes, toda vez que tanto el orden jurídico local, como el orden jurídico constitucional cuentan con plenas facultades para diseñar mecanismos expeditos de control de regularidad constitucional que aseguren que las resoluciones del organismo de acceso a la información pública se ciña a las facultades que les han sido conferidas y respete las competencias y garantías institucionales de los sujetos obligados, así como los derechos de las personas reconocidos en la Constitución local y en la norma suprema, en sus respectivos casos.

Al respecto, debe recordarse que en el caso Claude Reyes y otros vs. Chile, la Corte Interamericana determinó que es inconvencional la ausencia de un recurso efectivo frente a las resoluciones que obstaculizan el ejercicio del derecho a la información. Para la CIDH, el Estado debe garantizar que, ante la denegatoria de información bajo el control estatal, exista un recurso judicial sencillo, rápido y efectivo que permita que se determine si se produjo una vulneración del derecho del solicitante de información y, en su caso, se ordene al órgano correspondiente la entrega de la información. En este ámbito, la CIDH agregó, dicho recurso debe ser sencillo y rápido, tomando en cuenta que la celeridad en la entrega de la información es indispensable en esta materia. En tal sentido, la Corte Interamericana resaltó que de acuerdo a lo dispuesto en los artículos 20. y 25.2.b) de la Convención si el Estado parte en la Convención no tiene un recurso judicial para proteger efectivamente el derecho tiene que crearlo. El Tribunal interamericano concluyó que el Estado chileno violó el derecho a la protección judicial consagrado en el artículo 25.1 de la Convención Americana, en relación con el artículo 1.1 de la misma, en perjuicio de Marcel Claude Reyes, Arturo Longton Guerrero y Sebastián Cox Urrejola, al no garantizarles un recurso sencillo, rápido y efectivo que les amparara ante actuaciones estatales que alegaban como violatorias de su derecho de acceso a la información bajo el control del Estado.

Luego, la acción de inconstitucionalidad 56/2009, pendiente de resolverse, es de la mayor importancia, toda vez que la revisión de las resolu- 
ciones que emiten los órganos u organismos especializados en la materia podría aniquilar el derecho de acceso efectivo y oportuno a la información pública, máxime que la experiencia ha evidenciado que la posibilidad de que los sujetos obligados a proporcionar información impugnen dichas decisiones ante tribunales ordinarios, allegados o no al Poder Ejecutivo, tiende a retrasar, obstaculizar, politizar y, en algunos casos, a nulificar ese derecho fundamental en perjuicio de los ciudadanos, con un alto precio para el Estado democrático de derecho. 